\title{
Pengaruh Kemampuan dan Pengetahuan Managerial serta Lingkungan Eksternal terhadap Investasi Teknologi di Era 4.0 pada UKM di Kota Surabaya
}

\author{
Ayouvi Poerna Wardhanie, Didiet Anindita Arnandy \\ Universitas Dinamika \\ e-mail: ayouvi@dinamika.ac.id,didiet@dinamika.ac.id
}

\begin{abstract}
This research was conducted to examine the relationship between managerial skills, managerial knowledge and the external environment on technology investment in the era of the industrial revolution 4.0 in SMEs in the city of Surabaya. Sampling was carried out using survey techniques through questionnaires distributed to respondents. The population determined in this study were SMEs in the city of Surabaya. The number of samples taken was 36 SMEs in the city of Surabaya. Data analysis was performed using multiple regression tests through the Statistical Package for Social Sciences (SPSS) software. The results of this study indicate that managerial ability and the external environment partially do not have a significant positive effect on technology investment, while managerial knowledge has a significant positive effect on technology investment. However, simultaneously managerial ability, managerial knowledge and the external environment have a significant positive effect on technology investment.
\end{abstract}

Keywords: managerial ability, manajerial knowledge, external environment, technology investment

\section{PENDAHULUAN}

Daya saing Indonesia di mata dunia hampir mengalami penurunan. Hal ini tertulis pada laporan World Economy Forum (WEF) tahun 2010, Global Competitiveness Index Indonesia. Pada tahun 2010-2011, menduduki posisi ke-44 dari 139 negara, tahun 2011-2011 menduduki posisi ke-46 dari 142 negara, dan tahun 2012-2013 menduduki posisi ke-50 dari 144 negara. Akan tetapi, hal ini langsung berubah pada periode 2013-2014, yang mana peringkat Indonesia mengalami peningkatan secara drastis, yaitu pada peringkat ke-38. Hal ini menunjukkan bahwa Indonesia tangguh dalam menghadapi persaingan, terlebih kembali di era revolusi 4.0 saat ini.

Di era ini, Indonesia memiliki peluang yang besar untuk lebih maju dalam persaingan. Terlebih lagi terkait persaingan dalam memperluas target pasar yang saat ini semakin sulit di mana seiring adanya perkembangan teknologi yang secara otomatis berdampak pada peningkatan permintaan dan penawaran produk (Candraningrat, et al., 2018). Hal ini diwujudkan melalui sektor bisnis terutama pada usaha kecil dan menengah (UKM). UKM ialah suatu bentuk usaha yang melakukan jual beli produk yang diperoleh dari industri besar (Santoso, 2017). Berdasarkan UU No. 20 Tahun 2008, UKM terdiri dari dua jenis yakni usaha kecil dan usaha menengah. Usaha kecil ialah suatu bentuk usaha dengan penghasilan bersih di atas 50 juta sampai dengan 500 juta di luar tanah dan bangunan serta dengan hasil penjualan per tahun di atas 300 juta sampai dengan 2,5 miliar. Usaha menengah ialah suatu bentuk usaha dengan penghasilan bersih di atas 500 juta sampai dengan 10 mmiliar di luar tanah dan bangunan usaha serta dengan hasil penjualan per tahun di atas 2,5 sampai dengan 50 miliar.

Di Indonesia, UKM mengalami perkembangan sangat pesat setelah terjadinya penurunan ekonomi yang dimulai pada tahun 1997. Oleh 
karena itu, UKM dianggap sebagai penyelamat perekonomian. Dikatakan demikian karena UKM mampu mengurangi tingkat pengangguran dan menyediakan lapangan kerja. Selain itu, UKM juga berkontribusi dalam pendapatan baik daerah maupun negara. Di samping itu, Candraningrat, et al. (2018) berpendapat bahwa UKM berperan penting terhadap perekonomian Indonesia terutama terkait pengangguran dan meningkatkan normalitas usaha yang berkelanjutan. Era revolusi industri 4.0 ini membawa berbagai ancaman bagi negara Indonesia, karena semakin mudah produk asing yang masuk. Terlebih kembali bahwa produk-produk tersebut memiliki kualitas yang lebih baik. Berawal dari hal tersebut, mendorong para pelaku UKM untuk dapat meningkatkan kualitas produk agar dapat bersaing dengan berbagai produk asing yang masuk.

Kota Surabaya adalah salah satu kota yang mengalami perkembangan pesat terkait UKM. Pada tahun 2008, jumlah UKM di Surabaya mencapai 4,2 juta, tahun 2012 mencapai 6,8 juta dan tahun 2016 mencapai 9,59 juta (Aquinus, 2018). Dengan menyadari peluang UKM di era industri 4.0 saat ini, diperlukan berbagai upaya agar dapat unggul dalam persaingan. Salah satu upaya yang dapat dilakukan yaitu investasi teknologi. Salah satu tujuan melakukan investasi teknologi adalah untuk meningkatkan efisiensi dan efektivitas kegiatan operasional, mulai dari pengadaan hingga pengiriman yang mana agar dapat unggul dalam persaingan. Menurut Annosi (2019) dalam memutuskan tersebut, ada tiga hal sebagai penentu keputusan pihak UKM terkait investasi teknologi antara lain kemampuan manajerial, pengetahuan manajerial dan lingkungan eksternal. Selain itu, ketiga hal tersebut juga dianggap sebagai faktor yang berpengaruh terhadap keberhasilan perancangan, pembuatan, penerapan dan pemeliharaan pada teknologi yang digunakan. Berdasarkan penjelasan tersebut, di- perlukan penelitian tentang Pengaruh Kemampuan dan Pengetahuan Managerial serta Lingkungan Eksternal terhadap Investasi Teknologi di Era 4.0 pada UKM di Kota Surabaya.

\section{KERANGKA KONSEPTUAL/METODOLOGI PENELITIAN}

Berdasarkan permasalahan yang dikaji, penelitian ini termasuk jenis penelitian kausalitas. Penelitian kausalitas ialah penelitian yang mengkaji hubungan sebab akibat antara variabel bebas dengan variabel terikat (Sugiyono, 2012), sedangkan berdasarkan jenis data yang diperoleh penelitian ini termasuk jenis penelitian kuantitatif. Penelitian kuantitatif ialah penelitian yang mengambil data dalam bentuk angka yang selanjutnya dilakukan analisis statistik. Penelitian ini terdiri dari tiga variabel bebas yakni kemampuan manajerial $\left(X_{1}\right)$, pengetahuan manajerial $\left(X_{2}\right)$, dan lingkungan eksternal $\left(\mathrm{X}_{3}\right)$ dengan satu variabel terikat yakni investasi teknologi $(\mathrm{Y})$.

Populasi yang ditentukan dalam penelitian ini yaitu semua UKM yang ada di Kota Surabaya. Jumlah sampel yang diambil sebanyak 35 UKM yang ada di Surabaya, Hal ini dikarenakan keterbatasan jumlah UKM yang berada di Kota Surabaya, sehingga hanya diambil sebanyak 35 UKM. Kerangka pemikiran dalam penelitian ini dapat dilihat pada Gambar 1.

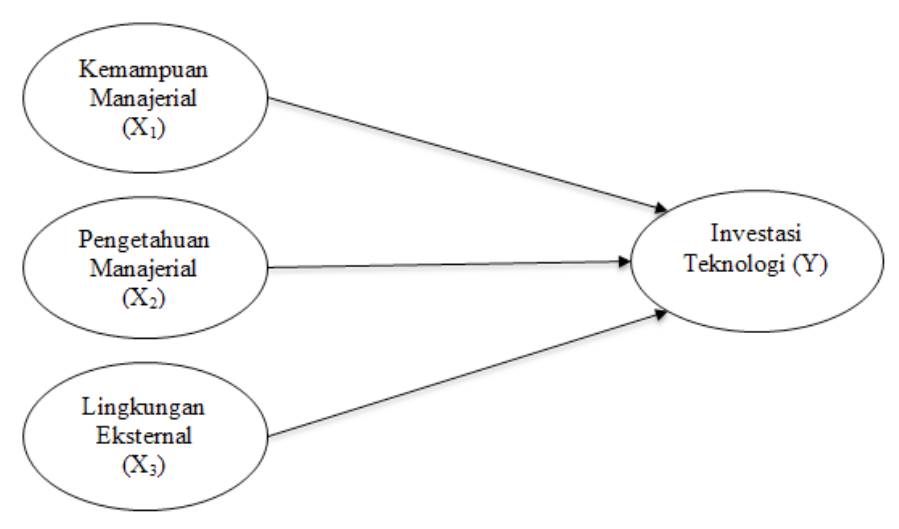

Gambar 1 Kerangka Pemikiran 
Ayouvi Poerna Wardhanie, Didiet Anindita Arnandy, Pengaruh Kemampuan dan Pengetahuan Managerial serta Lingkungan Eksternal terhadap Investasi Teknologi di Era 4.0 pada UKM di Kota Surabaya

Hipotesis dalam penelitian ini sesuai kerangka pemikiran yang ada dapat diketahui sebagai berikut.

$\mathrm{H}_{1}$ : Kemampuan manajerial berpengaruh signifikan dan positif terhadap investasi teknologi.

$\mathrm{H}_{2}$ : Pengetahuan manajerial berpengaruh signifikan dan positif terhadap investasi teknologi.

$\mathrm{H}_{3}$ : Lingkungan eksternal berpengaruh signifikan dan positif terhadap investasi teknologi.

$\mathrm{H}_{4}$ : Kemampuan manajerial, pengetahuan manajerial dan lingkungan eksternal berpengaruh signifikan dan positif terhadap investasi teknologi.

\section{HASIL DAN PEMBAHASAN}

\section{Uji Instrumen Data}

\section{Uji Validitas}

Tabel 1 Hasil Uji Validitas

\begin{tabular}{|c|c|c|c|}
\hline Item & $\mathbf{r}_{\text {hitung }}$ & $\mathbf{r}_{\text {tabel }}$ & Hasil \\
\hline Kemampuan Manajerial 1 & 0,449 & \multirow{13}{*}{0,329} & Valid \\
\hline Kemampuan Manajerial 2 & 0,521 & & Valid \\
\hline Kemampuan Manajerial 3 & 0,439 & & Valid \\
\hline Kemampuan Manajerial 4 & 0,487 & & Valid \\
\hline Kemampuan Manajerial 5 & 0,586 & & Valid \\
\hline Pengetahuan Manajerial 1 & 0,561 & & Valid \\
\hline Pengetahuan Manajerial 2 & 0,789 & & Valid \\
\hline Pengetahuan Manajerial 3 & 0,700 & & Valid \\
\hline Lingkungan Eksternal 1 & 0,393 & & Valid \\
\hline Lingkungan Eksternal 2 & 0,419 & & Valid \\
\hline Lingkungan Eksternal 3 & 0,392 & & Valid \\
\hline Investasi Teknologi 1 & 0,744 & & Valid \\
\hline Investasi Teknologi 2 & 0,687 & & Valid \\
\hline
\end{tabular}

Berdasarkan hasil uji validitas dapat diketahui bahwa seluruh angket dalam penelitian ini valid karena memiliki $r_{\text {hitung }}>r_{\text {tabel }}$ sebesar 0,329, sehingga angket dalam penelitian ini dapat digunakan ulang untuk penelitian selanjutnya dan dapat dilakukan uji reliabilitas.

\section{Uji Reliabilitas}

Tabel 2 Hasil Uji Reliabilitas

\begin{tabular}{|l|c|c|c|}
\hline \multicolumn{1}{|c|}{ Variabel } & $\begin{array}{c}\text { Nilai } \\
\text { Cronbach' } \\
\text { s Alpha }\end{array}$ & $\begin{array}{c}\text { Nilai } \\
\text { Minimum } \\
\text { Cronbach's } \\
\text { Alpha }\end{array}$ & Hasil \\
\hline $\begin{array}{l}\text { Kemampuan } \\
\text { Manajerial }\end{array}$ & 0,784 & 0,60 & Reliabel \\
\cline { 1 - 1 } $\begin{array}{l}\text { Pengetahuan } \\
\text { Manajerial }\end{array}$ & 0,749 & & Reliabel \\
\cline { 1 - 2 } $\begin{array}{l}\text { Lingkungan } \\
\text { Eksternal }\end{array}$ & $0 ., 727$ & & Reliabel \\
\hline $\begin{array}{l}\text { Investasi } \\
\text { Teknologi }\end{array}$ & 0,873 & & Reliabel \\
\hline
\end{tabular}

Berdasarkan hasil uji reliabilitas dapat diketahui bahwa seluruh jawaban responden pada variabel penelitian bersifat reliabel karena memiliki nilai Cronbach's Alpha > 0,60 sehingga jawaban responden yang ada dapat dipercaya dan dapat dilakukan uji prasyarat analisis.

\section{Uji Prasyarat Analisis}

\section{Uji Normalitas}

Tabel 3 Hasil Uji Normalitas

\begin{tabular}{|l|l|r|}
\hline \multicolumn{2}{|c|}{ One-Sample Kolmogorov-Smirnov Test } \\
\hline \multicolumn{2}{|c|}{} & $\begin{array}{c}\text { Unstandardized } \\
\text { Residual }\end{array}$ \\
\hline $\mathrm{N}$ & 36 \\
\hline \multirow{2}{|c|}{$\begin{array}{l}\text { Normal } \\
\text { Parameters }\end{array}$} & Mean & 0,0000000 \\
\cline { 2 - 3 } $\begin{array}{l}\text { Most Extreme } \\
\text { Differences }\end{array}$ & Std. Deviation & 1,00442150 \\
\cline { 2 - 3 } & Absolute & 0,125 \\
\cline { 2 - 3 } & Nositive & 0,091 \\
\hline Test Statistic & Negative & $-0,125$ \\
\hline Asymp. Sig. (2-tailed) & 0,125 \\
\hline
\end{tabular}

Berdasarkan hasil uji normalitas dapat diketahui bahwa data penelitian ini berdistribusi normal karena memiliki nilai Asymp. Sig. (2tailed) $>0,05$, sehingga dapat dilakukan uji multikolinieritas. 


\section{Uji Multikolinearitas}

Tabel 4 Hasil Uji Multikolinearitas

\begin{tabular}{|l|c|c|l|}
\hline \multicolumn{1}{|c|}{ Variabel } & VIF & Tolerance & \multicolumn{1}{c|}{ Hasil } \\
\hline $\begin{array}{l}\text { Kemampuan } \\
\text { Manajerial }\end{array}$ & 1,234 & 0,811 & $\begin{array}{l}\text { Tidak Terjadi } \\
\text { Multikolinearitas }\end{array}$ \\
\hline $\begin{array}{l}\text { Pengetahuan } \\
\text { Manajerial }\end{array}$ & 1,225 & 0,817 & $\begin{array}{l}\text { Tidak Terjadi } \\
\text { Multikolinearitas }\end{array}$ \\
\hline $\begin{array}{l}\text { Investasi } \\
\text { Teknologi }\end{array}$ & 1,050 & 0,953 & $\begin{array}{l}\text { Tidak Terjadi } \\
\text { Multikolinearitas }\end{array}$ \\
\hline
\end{tabular}

Berdasarkan hasil uji multikolinearitas dapat diketahui bahwa tidak terjadi multikolinearitas karena seluruh variabel bebas memiliki nilai Tolerance $>0,1$ dan nilai VIF $<10$ sehingga dapat dilakukan uji heteroskedastisitas.

\section{Uji Heteroskedastisitas}

Tabel 5 Hasil Uji Heteroskedastisitas

\begin{tabular}{|l|c|l|}
\hline \multicolumn{1}{|c|}{ Variabel } & Sig. & \multicolumn{1}{c|}{ Hasil } \\
\hline $\begin{array}{l}\text { Kemampuan } \\
\text { Manajerial }\end{array}$ & 0,532 & $\begin{array}{l}\text { Tidak Terjadi } \\
\text { Heteroskedastisitas }\end{array}$ \\
\hline $\begin{array}{l}\text { Pengetahuan } \\
\text { Manajerial }\end{array}$ & 0,434 & $\begin{array}{l}\text { Tidak Terjadi } \\
\text { Heteroskedastisitas }\end{array}$ \\
\hline $\begin{array}{l}\text { Investasi } \\
\text { Teknologi }\end{array}$ & 0,160 & $\begin{array}{l}\text { Tidak Terjadi } \\
\text { Heteroskedastisitas }\end{array}$ \\
\hline
\end{tabular}

Berdasarkan hasil uji heteroskedastisitas dapat diketahui tidak terjadi heteroskedastisitas karena seluruh variabel bebas memiliki nilai sig.> 0,05, sehingga dapat dilakukan uji uji linieritas.

\section{Uji Linearitas}

Tabel 6 Hasil Uji Linearitas

\begin{tabular}{|l|c|c|}
\hline \multicolumn{1}{|c|}{ Variabel } & Sig. & Hasil \\
\hline $\begin{array}{l}\text { Kemampuan } \\
\text { Manajerial }\end{array}$ & 0,143 & Linear \\
\hline $\begin{array}{l}\text { Pengetahuan } \\
\text { Manajerial }\end{array}$ & 0,503 & Linear \\
\hline $\begin{array}{l}\text { Investasi } \\
\text { Teknologi }\end{array}$ & 0,126 & Linear \\
\hline
\end{tabular}

Berdasarkan hasil uji linieritas dapat diketahui bahwa seluruh variabel bebas dalam penelitian ini berhubungan linear karena memiliki nilai sig. $<0,05$, sehingga dapat dilakukan uji regresi berganda.

\section{Uji Regresi Berganda}

\section{Koefisien Determinasi (Adjusted $R^{2}$ )}

Tabel 7 Koefisien Determinasi (Adjusted R²)

\begin{tabular}{|c|c|c|c|c|}
\hline \multicolumn{5}{|c|}{ Model Summary } \\
\hline Model & R & $\begin{array}{c}\text { R } \\
\text { Square }\end{array}$ & $\begin{array}{c}\text { Adjusted } \\
\text { R Square }\end{array}$ & $\begin{array}{c}\text { Std. Error of } \\
\text { the Estimate }\end{array}$ \\
\hline 1 & 0,769 & 0,592 & 0,554 & 1,050 \\
\hline
\end{tabular}

Berdasarkan hasil koefisien determinasi dapat diketahui bahwa variabel bebas mampu menjelaskan variabel terikat sebesar 0,554 $(55,4 \%)$. Hal ini tertera pada nilai Adjusted $R^{2}$ sebesar 0,554 (55,4\%), sehingga sebanyak 0,446 $(44,6 \%)$ variabel terikat dijelaskan oleh variabel bebas lain di luar penelitian ini. Langkah selanjutnya dilakukan uji $\mathrm{F}$ (uji serentak).

\section{Uji F (Uji Serentak)}

\section{Tabel 8 Hasil Uji F}

\begin{tabular}{|c|c|c|c|c|c|c|}
\hline \multicolumn{7}{|c|}{ ANOVA } \\
\hline \multicolumn{2}{|c|}{ Model } & $\begin{array}{l}\text { Sum of } \\
\text { Squares }\end{array}$ & $\mathrm{df}$ & $\begin{array}{l}\text { Mean } \\
\text { Square }\end{array}$ & F & Sig. \\
\hline \multirow[t]{3}{*}{1} & Reg. & 51,245 & 3 & 17,082 & 15,480 & 0,000 \\
\hline & Res. & 35,310 & 32 & 1,103 & & \\
\hline & Total & 86,556 & 35 & & & \\
\hline
\end{tabular}

Berdasarkan hasil uji $\mathrm{F}$ dapat diketahui bahwa seluruh variabel bebas berpengaruh signifikan dan positif terhadap variabel terikat secara serentak karena memiliki nilai $\mathrm{F}_{\text {hitung }} 15,480>$ $\mathrm{F}_{\text {tabel }}$ 2,901 dan nilai sig. $<0,05$. Langkah selanjutnya dilakukan uji t (uji individual). 
Ayouvi Poerna Wardhanie, Didiet Anindita Arnandy, Pengaruh Kemampuan dan Pengetahuan Managerial serta Lingkungan Eksternal terhadap Investasi Teknologi di Era 4.0 pada UKM di Kota Surabaya

Uji $t$ (Uji Individual)

Tabel 9 Hasil Uji $\mathbf{t}$

\begin{tabular}{|c|c|c|c|c|c|c|}
\hline \multicolumn{7}{|c|}{ Coefficients $^{\mathrm{a}}$} \\
\hline & \multirow{2}{*}{ Model } & \multicolumn{2}{|c|}{$\begin{array}{c}\text { Unstandardized } \\
\text { Coefficients }\end{array}$} & \multirow{2}{*}{$\begin{array}{c}\begin{array}{c}\text { Standardized } \\
\text { Coefficients }\end{array} \\
\text { Beta }\end{array}$} & \multirow{2}{*}{$\mathbf{t}$} & \multirow{2}{*}{ Sig. } \\
\hline & & B & $\begin{array}{l}\text { Std. } \\
\text { Error }\end{array}$ & & & \\
\hline \multirow[t]{4}{*}{1} & (Constant) & 0,531 & 2,004 & & 0,265 & 0,793 \\
\hline & KM & 0,071 & 0,085 & 0,106 & 0,846 & 0,404 \\
\hline & $\mathrm{PM}$ & 0,556 & 0,096 & 0,721 & 5,771 & 0,000 \\
\hline & $\overline{\mathrm{LE}}$ & $-0,097$ & 0,092 & $-0,122$ & $-1,051$ & 0,301 \\
\hline
\end{tabular}

*KM = Kemampuan Manajerial

$\mathrm{PM}=$ Pengetahuan Manajerial

LE $=$ Lingkungan Eksternal

\section{Diskusi}

$\mathrm{H}_{1}$ : Kemampuan manajerial berpengaruh signifikan dan positif terhadap investasi teknologi

Hipotesis pertama mengkaji hubungan antara variabel KM dengan variabel IT yang dapat diketahui bahwa KM tidak berpengaruh signifikan dan positif terhadap IT karena memiliki nilai sig. 0,404>0,05 dan memiliki nilai $t_{\text {stat }}$ sebesar $0,846<\mathrm{t}_{\text {tabel }}$ sebesar 2,037. Dengan demikian, hipotesis yang menyatakan "kemampuan manajerial berpengaruh positif signifikan terhadap investasi teknologi”, ditolak.

$\mathrm{H}_{2}$ : Pengetahuan manajerial berpengaruh signifikan dan positif terhadap investasi tekno$\operatorname{logi}$

Hipotesis kedua mengkaji hubungan antara variabel PM dengan variabel IT yang dapat diketahui bahwa PM berpengaruh signifikan dan positif terhadap IT karena memiliki nilai sig. $0,000>0,05$ dan memiliki nilai $\mathrm{t}_{\text {stat }}$ sebesar $5,771<\mathrm{t}_{\text {tabel }}$ sebesar 2,037. Dengan demikian, hipotesis yang menyatakan "pengetahuan manajerial berpengaruh positif signifikan terhadap investasi teknologi”, diterima.
$\mathrm{H}_{3}$ : Lingkungan eksternal berpengaruh signifikan dan positif terhadap investasi teknologi

Hipotesis ketiga mengkaji hubungan antara variabel LE dengan variabel IT yang dapat diketahui bahwa LE tidak berpengaruh signifikan dan positif terhadap IT karena memiliki nilai sig. 0,301>0,05 dan memiliki nilai $\mathrm{t}_{\text {stat }}-1,051$ $<\mathrm{t}_{\text {tabel }}$ sebesar 2.037. Dengan demikian, hipotesis yang menyatakan "lingkungan eksternal berpengaruh positif signifikan terhadap investasi teknologi”, ditolak.

$\mathrm{H}_{4}$ : Kemampuan manajerial, pengetahuan manajerial dan lingkungan eksternal berpengaruh signifikan dan positif terhadap investasi teknologi

Hipotesis keempat mengkaji hubungan antara variabel KM, PM dan LE dengan variabel IT yang dapat diketahui bahwa variabel KM, PM dan LE secara serentak berpengaruh signifikan dan positif terhadap IT karena memiliki nilai sig. sebesar $0,000<0,05$ dan memiliki nilai $\mathrm{F}_{\text {hitung }} 15,480>\mathrm{F}_{\text {tabel }}$ sebesar 2,901. Dengan demikian, hipotesis yang menyatakan "kemampuan manajerial, pengetahuan manajerial dan lingkungan eksternal berpengaruh positif dan signifikan terhadap investasi teknologi”, diterima.

\section{KESIMPUILAN}

Kesimpulan yang dapat diambil atas dasar hasil dan diskusi yang telah dijelaskan sebagai berikut. Investasi teknologi pada UKM di Kota Surabaya tidak dipengaruhi oleh kemampuan manajerial pemilik UKM. Investasi teknologi pada UKM di Kota Surabaya harus didasarkan pada pengetahuan manajerial dari pemilik UKM. Investasi teknologi pada UKM di Kota Surabaya tidak terpengaruh oleh lingkungan eksternal. 
Investasi teknologi pada UKM di Kota Surabaya lebih tepat jika didasarkan pada kemampuan manajerial, pengetahuan manajerial, dan lingkungan eksternal secara bersamaan.

\section{DAFTAR PUSTAKA}

Annosia, M.C., Brunettab, F., Montic, A., \& Nat, F. 2019. Is the Trend Your Friend? An Analysis of Technology 4.0 Investment Decisions in Agricultural SMEs. Computers in Industry, 59-71.

Aquinus, Thomas. 2018. Pertumbuhan UKM Surabaya Terus Meningkat. preneur.trubus. id diakses pada 16 Agustus 2019.

Candraningrat, Adrianto, Y.R., \& Wibowo, J. 2018. Pengabdian kepada Masyarakat bagi Kelompok Tani Elok Mekar Sari Surabaya. Jurnal Pengabdian Masyarakat LPPM Untag Surabaya, Vol. 03, No. 01, hal 1-6.
Candraningrat, Oktaviani, \& Suhandiah, S. 2018. Analysis of the Success Factors for MSME Succession in Surabaya: A Principal Component Analysis. Journal of Economics, Business, and Accountancy Ventura, Vol. 21, No. 2.

Santoso, R., Candraningrat, \& Binawati, L. 2017. Elemen Kecerdasan Wirausaha untuk Meningkatkan Kinerja Industri Kecil dan Menengah (IKM) di Surabaya. Bisnis dan Manajemen (BISMA), Volume 10, Nomor 1 .

Sugiyono. 2012. Metode Penelitian Kuantitatif Kualitatif dan R\&D. Bandung: Alfabeta. Undang-Undang Republik Indonesia Nomor 20 Tahun 2008 tentang Usaha Mikro, Kecil, dan Menengah.

www.mission-indonesia.org diakses pada 15 Agustus 2019. 